\title{
Olga Bauer y Zenobia Camprubí. Historia de una amistad
}

\section{Olga Bauer and Zenobia Camprubí. Story of a Friendship}

\author{
Ricardo Muñoz Solla \\ Universidad de Salamanca - IEMYRHd \\ solla@usal.es \\ ORCID iD: https://orcid.org/0000-0002-9263-8401
}

\section{RESUMEN}

Este artículo tiene por objeto presentar una semblanza biográfica de Olga Bauer de Gunzburg, judía de origen ruso y esposa del fundador y primer presidente de la Comunidad Judía de Madrid en 1917, Ignacio Bauer. La temprana integración de Olga Bauer en el ambiente cultural del Madrid de los años veinte le permitió compartir con otras mujeres similares inquietudes intelectuales. El artículo abordará, en concreto, el origen y desarrollo de la relación de amistad que estableció con Zenobia Camprubí, tal y como se desprende de la correspondencia entre ambas y otros materiales inéditos. Del mismo modo, se ofrecerán algunas otras noticias sobre sus círculos literarios.

Palabras Clave: Olga Bauer; Zenobia Camprubí; mujeres judías; epistolarios; Madrid.

\begin{abstract}
This article aims to present a biographical sketch of Olga Bauer de Gunzburg, a Jewish Russian woman and wife of the founder and first president of the Jewish Community of Madrid in 1917, Ignacio Bauer. The early integration of Olga Bauer within the cultural environment of Madrid in the 1920s allowed her to create important networks with other women sharing her intellectual interests. This article addresses, in particular, the origin and development of the friendship between Olga and Zenobia Camprubí through a glance at her private correspondence and other unpublished material. Some other novelties about her literary circles are also disclosed.
\end{abstract}

Key words: Olga Bauer; Zenobia Camprubí; Jewish women; Epistolaries; Madrid.

\section{INTRODUCCIÓN}

El propósito de este trabajo es ofrecer algunos de los resultados parciales de un proyecto de investigación en curso que aborda la historia de la comuni- 
dad judía de Madrid durante la primera mitad del siglo XX. Trataré de esclarecer algunos aspectos biográficos de una mujer inédita, como fue Olga Bauer, mujer del fundador de la comunidad judía de Madrid, Ignacio Bauer y Landauer (1891-1961). La trayectoria vital de Olga está relacionada no solo con la historia de la comunidad judía madrileña, sino también con el ambiente literario de la España de los años veinte y treinta, a través de su amistad con Zenobia Camprubí, la mujer de Juan Ramón Jiménez. Con ello, se pretende otorgar un nuevo protagonismo a Olga Bauer cuyo interés ha sido oscurecido por la constante omnipresencia de su marido. Esta cuestión debe contextualizarse convenientemente dentro de la revisión historiográfica que en las últimas décadas viene realizándose sobre el papel ejercido por un gran número de mujeres en el desarrollo intelectual de la España de la primera mitad del siglo XX: mujeres influyentes y olvidadas, «jamás mencionadas en los libros sobre historia de la cultura femenina y feminista española, auténticas presencias fantasmales sin las cuales no se puede entender el desarrollo de la cultura española en el siglo XX» (Capdevila-Argüelles 2013, 17).

\section{Olga Bauer de Gunzburg (1897-1986)}

¿Quién fue Olga Bauer y qué relación tuvo con el matrimonio de los Jiménez? ${ }^{1}$. Olga de Gunzburg pertenecía a una familia acomodada de banqueros de origen ruso. Nacida en San Petersburgo en 1897, fue la tercera hija del matrimonio entre Rosa Warburg (1870-1922) y Alexander (Moses) de Gunzburg (1869-1948) y nieta del banquero barón Horace de Gunzburg, director del Russian Imperial Bank en San Petersburgo, y agente de los Rothschild y Warburg en Rusia. Ambas fueron dos destacadas familias judías de la Europa del siglo XIX (Frankel 1981; Chernow 1993). Ante la creciente presión bolchevique en Rusia, la familia Gunzburg emigró en 1918 a Hamburgo, para establecerse finalmente en París, donde entró en contacto con algunos miembros de la familia Rothschild. Sin duda, esta conexión fue la que propició el conocimiento y matrimonio de Olga con Ignacio Bauer en 1921 y el posterior establecimiento de los recién casados en Madrid.

Ignacio Bauer, que había nacido en Madrid en 1891, era por entonces un joven financiero judío perteneciente a la familia de los Bauer, oriunda de Hun-

${ }^{1}$ No existe aún una biografía actualizada sobre Olga Bauer. J. Israel Garzón ha sido quien más atención ha dedicado a la familia de los Bauer y a la historia de la comunidad judía de Madrid. Sus múltiples obras y artículos sobre el tema aparecen en la bibliografía final. Algunos datos y fotografías de Olga Bauer han sido proporcionados por su sobrina, Dra. Katia Guth-Dreyfus, antigua conservadora del Jüdische Museum de Basilea. A ella y a su familia agradezco enormemente su interés por esta investigación, sin el cual no se podría haber llevado a cabo. 


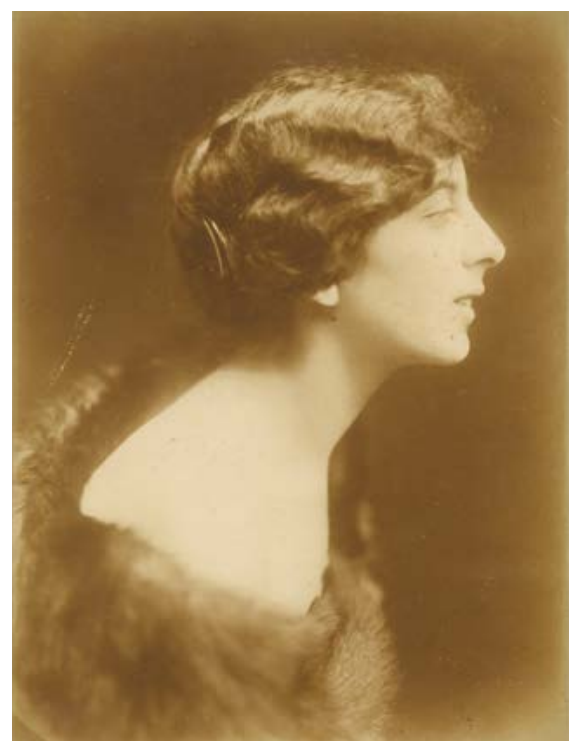

Fото 1. Olga de Gunzburg ca. 1918

(C) Herederos de Juan Ramón Jiménez

gría, y que se había establecido en España a finales del siglo XIX (Garzón 2011, 34-47; Lisbona 1993, 29). Ignacio se había hecho cargo de las tareas de representación de la casa Rothschild en Madrid, tras el fallecimiento en 1916 de su padre, Gustavo Bauer Morpurgo. Su privilegiada posición económica en el Madrid de los años veinte le permitió relacionarse con lo más granado de la sociedad del momento, integrándose con facilidad en los ambientes de la alta sociedad española y de la clase política del país. Ignacio se convirtió en una de las figuras que mayor interés mostraron en impulsar la vida judía madrileña que, hasta entonces, carecía de cualquier tipo de estructura comunal y recursos materiales (Garzón 1996, 33; 2001, 31). Tras su matrimonio con Olga Bauer, ambos ejercieron de anfitriones y organizadores de un gran número de actos culturales, reuniones y tertulias políticas y literarias desde su residencia madrileña en el conocido Palacio de San Bernardo y en el Palacio de La Granja en Segovia. Como se señalará más adelante, la formación universitaria de Olga y su fácil capacidad de adaptación le permitieron integrarse sin problemas en la sociedad madrileña que frecuentaba su marido. 
Por la sensibilidad que siempre demostró hacia los temas humanísticos y literarios Ignacio Bauer desarrolló una importante labor de mecenazgo y difusión cultural, en la que no faltaron donaciones de objetos valiosos a la Real Academia de la Historia (Maier 2005, 57) y al Museo Arqueológico Nacional (Sánchez-Gómez 1990, 68). Aunque Ignacio tenía cierto afán de ser prestigioso y reconocido entre sus contemporáneos, no cabe duda de que no solo contribuyó a su propio éxito. Entre las múltiples actividades impulsadas por él, debe señalarse que fue el impulsor y socio de uno de los grupos editoriales más prestigiosos del momento: la Editorial Ibero-Africano-Americana, que a finales de los años veinte, pasó a denominarse Compañía Ibero-Americana de Publicaciones, conocida como la CIAP, sociedad limitada de la empresa Bauer y Compañía (López-Morell y Molina Abril 2012, 116). La editorial, además de incluir en su nómina a la mayor parte de los literatos del momento, publicó también muchos de los trabajos de recopilación e investigación realizados por él mismo, ya que era un aficionado africanista del protectorado español, así como algunas revistas de temática judaica, como La Revista de la Raza y las publicaciones y estatutos de la Casa Universal de los Sefardies, de la que también fue fundador.

La relación de los Bauer con los Jiménez puede entenderse si se tiene en cuenta el papel que ejerció la CIAP como plataforma de publicación de las grandes obras de la literatura española de esa época. En 1929 Juan Ramón Jiménez había firmado un contrato con la editorial por la que se le cedía el derecho de publicar todas sus obras bajo la denominación de Obras Completas, con el acuerdo de sacar un tomo por año (Sánchez García 2003, 312). Pero lo cierto es que, profesionalmente hablando, el proyecto resultó un fracaso. Juan Ramón se desengañó muy pronto de la nueva empresa al detectar que las ediciones eran de escasa calidad, con impresiones defectuosas.

En los años treinta, la CIAP se declaró en suspensión de pagos, quebrando definitivamente y provocando la ruina de esta empresa familiar. Estos acontecimientos, así como el inicio de la guerra civil en 1936, llevaron al matrimonio a abandonar temporalmente España, viviendo en Holanda durante dos años con una hermana de Olga, Irene de Vries Gunzburg (1910-2004)2. Ignacio regresó en 1939 y Olga se sumaría de nuevo en 1940 después de haber cuidado durante algunos meses a su padre inválido en el sur de Francia. La situación, a finales de los años 40, no fue fácil para el matrimonio. En una carta inédita de Rafael Cansinos Assens a Abraham S. Yahuda, del 28 de agosto de 1949, aquel daba cuenta de los sinsabores de los Bauer:

El señor Bauer no reside tampoco habitualmente en Madrid; no sé si sabrá usted que se arruinó casi por completo en el negocio de la CIAP, quebró la banca, tuvo que vender el palacio de la calle San Bernardo, donde ahora hay instalado un

\footnotetext{
2 En 1936 se casó con Robert Ary de Vries, primer director del museo Mauritshuis (La Haya).
} 
centro de Falange y él logró que lo nombrasen catedrático auxiliar de Geografía en el Instituto de Ceuta, adonde puede usted escribirle. El poco capital que le quedó, fue lo de su mujer, una rusa, según he oído decir³ .

El periodo de postguerra, tan estéril y difícil para el matrimonio en un Madrid asfixiado por el hambre y la pobreza, muy alejado del exquisito ambiente que conocieron en las décadas anteriores, les impulsó a abandonar España en 1951, estableciéndose en Basilea (Suiza), donde vivía otra de las hermanas de Olga, Vera Dreyfus de Gunzburg (1898-1971)4. Durante esos años Ignacio viajó ocasionalmente a Madrid, mostrando también un gran interés por los acontecimientos del Estado de Israel, y fue incluso propuesto para ser nombrado Cónsul General de Israel en España, hecho que no llegó a suceder. Pero la muerte de Ignacio Bauer en 1961 supuso para Olga un importante revés. Durante los más de veinte años que le sobrevivió -Olga Bauer murió en 1986intentó preservar la memoria de su marido cumpliendo una de las ilusiones que más le habían ocupado a Ignacio en los últimos años de su vida: la donación de su biblioteca y archivo a la Biblioteca Nacional de Israel.

\section{Los INICIOS}

Pero volvamos a los felices años veinte del recién creado matrimonio y a la efervescencia cultural que por aquel entonces vivía Madrid (Gesser 2015; Ribagorda 2009), surgida bajo el cobijo que ofrecían instituciones como el Casino de Madrid, las tertulias literarias del Café Gijón, El Círculo de Bellas Artes, el Ateneo de Madrid y, sobre todo la Residencia de Estudiantes (Pérez Villanueva 2011). En estos espacios, paralelos a la vida del judaísmo madrileño, aún casi clandestino, se movieron Ignacio y Olga, cada uno en la medida de sus posibilidades y, ante todo, dentro de los condicionamientos y espacios propios que la actividad intelectual imponía a hombres y mujeres.

Si bien la relación de Ignacio Bauer con Juan Ramón Jiménez fue fundamentalmente de carácter profesional, la establecida entre Olga y Zenobia Camprubí fue mucho más estrecha y se prolongó durante toda su vida, mucho después incluso del exilio de ambos matrimonios. El inexplorado mundo de lo que se ha llamado la genealogía feminista, aquel expresado mediante cartas y epistolarios, constituye una de las fuentes fundamentales para recorrer este capítulo de amistad entre Olga y Zenobia, que arroja a su vez interesantes noticias sobre sus vidas ${ }^{5}$.

Aunque se desconocen los detalles de sus primeros encuentros, los inicios de esta relación de amistad se remontan a poco antes de la llegada de Olga a

\footnotetext{
${ }^{3}$ Biblioteca Nacional de Israel, ARC, Ms. Var. Yah 3801463.

${ }^{4}$ Casada con Paul Israel Dreyfus.

${ }^{5}$ La correspondencia entre ambas ha sido editada por Cortés Ibáñez 2017.
} 
Madrid; ya en 1916, con motivo de la boda de Juan Ramón Jiménez y Zenobia, el 2 de marzo de ese año, Zenobia hacía referencia en su diario de recién casada al collar que Olga le había regalado para el enlace (Cortés 2012, 56).

Sin duda, el hecho de que ambas mujeres compartieran importantes vínculos con el extranjero y que frecuentaran los mismos ambientes favoreció la integración de Olga en el círculo de amistades de Zenobia. Ambas participaron asiduamente en el Lyceum Club Femenino Español, fundado por María de Maeztu en 1926 y del que durante varios años Zenobia fue secretaria (Pérez 2011). En carta de María Martos a Maeztu se cita a Olga Bauer como interesada en sus actividades (Cortés 2015, 40). El Lyceum celebraba sus primeras reuniones en la Residencia de Señoritas, anejo a la residencia de Estudiantes y fue un centro cultural que sirvió como plataforma para la emancipación de la mujer (Cuesta, Turrión y Merino 2015; Cueva y Márquez 2015).

Olga entra en casa de los Jiménez por primera vez, según relataba la misma Zenobia, a finales de 1931, en una cena que aquella organizó en homenaje a la pianista Ania Dorfmann (1899-1984). Dorfmann había nacido en Odessa (Rusia) y, al igual que Olga, se había desplazado a París donde había continuado sus estudios musicales a partir de 1916. Es posible que este origen común, así como el interés del propio Bauer en atraer a destacadas figuras de la música y, en especial, su gusto por la ópera, facilitaran el encuentro entre ambas (Ortiz de Urbina y Sobrino, 2005, 238). Es a partir de este momento cuando Zenobia y Olga empiezan a tratarse e intimaron mucho más a raíz del viaje que realizaron a Marruecos en la primavera de 1932. Ambas planearon este viaje de quince días al Marruecos español y francés aprovechando un acatarramiento de Juan Ramón Jiménez, que le obligó a permanecer en casa. Zenobia trataba asimismo de recuperarse de una reciente bronquitis. Las once cartas que Zenobia dirigió a Juan Ramón Jiménez durante estos meses nos informan de que visitaron Tetuán, Fez, Xauén, Alcazarquivir, Rabat, Casablanca, Marraquesh y Tánger. Viajaron acompañadas de Ignacio Bauer, buen conocedor de la región y con buenas amistades en Tetuán, como las familias judías de los Tubau o Ben Tata. En Tánger almorzaron con un amigo judío suyo, regresando por la noche al hotel. En Tetúan, el 21 de marzo de 1932, Zenobia recordaba lo siguiente:

Hoy después de un día de grandes paseos por el barrio moro y la Alcazaba, con un guía moro que nos proporcionó Tubau, nos sentamos un rato Olga y yo a disfrutar de la noche, el cielo azul, la luna llena y el magnífico lucero en la Plaza de España que es la edición españomoruna de la Plaza de las Monjas de Huelva, en eso llegó Ignacio Bauer de Ceuta y yo me volví al hotel a darme un baño tibio, porque las piedras de las calles morunas sólo pueden compararse al empedrado toledano (Domínguez Sío 2008, VII).

De entre los detalles de este viaje, llama la atención las críticas que Zenobia vierte sobre la persona de Ignacio, tildándole de «pesado y tonto». Al parecer, nunca las dejaba solas, señalando a continuación: «¡No sé como tiene 
ella la santa paciencia que tiene con él! ¡Es tan atrozmente el niño judío retrasado y un poco repugnante que estropea bastante el paisaje!» (Domínguez Sío 2010, 332). De ese mismo viaje se conservan además tres postales con notas de saludo que Bauer envió a Juan Ramón 6 .

\section{Poemas dedicados a Olga Bauer}

Una magnífica muestra de estos entresijos de amistad que cultivaron Olga y Zenobia, en este caso a través del propio Juan Ramón, son dos poemas del mismo dedicados a Olga y que en la actualidad se conservan en la Biblioteca Nacional de Israel. Son dos documentos inéditos fechados en 1933 y 1931 respectivamente, que se corresponden con esta primera época de amistad previa al exilio de los Jiménez.

El primero es un poema autógrafo, escrito en lápiz naranja, con cubierta en la que se inserta la dedicatoria. Se trata del poema "Álamo Penúltimo», que Juan Ramón incorporó al poemario La Estación Total, con un nuevo título, «La copa final»: "Contra el cielo inespresable / el álamo, ya amarillo, / instala la alta belleza / de su éstasis vespertino. / La luz se recoje en él / como en el nido tranquilo / de su eternidad. Y el álamo / termina bien en sí mismo» (Díaz de Castro 2007; Azam 1981).

El segundo documento es una reproducción fotoestática del poema «En flor 50», también publicado en La Estación Total y que está acompañado por una copia del célebre autorretrato de Juan Ramón Jiménez realizado por Joaquín Sorolla en 1916.

Los poemas que Juan Ramón Jiménez envió a Olga Bauer constituyen uno de los testimonios más valiosos del archivo personal que Ignacio Bauer donó a la Biblioteca Nacional de Israel entre cuyos papeles se encuentra este material que perteneció a Olga. El poema autógrafo «Álamo Penúltimo» resulta especialmente significativo, pues se trata de una versión original y dedicada que Juan Ramón Jiménez incluyó en 1946 en La Estación Total. El 5 de octubre de 1947, Olga Bauer refería a Zenobia Camprubí la emoción que le había producido el comprobar la inclusión en su obra de ese poema que había recibido de manos de Juan Ramón Jiménez:

Llegó por fin a Madrid La estación total con las cuatro canciones de la nueva $l u z$, que me ha emocionado mucho. Me impresionó profundamente el encontrar

\footnotetext{
${ }^{6}$ Archivo Histórico Nacional. Fondo Juan Ramón Jiménez, 324/5-7. Postales de Ignacio Bauer a Juan Ramón Jiménez. 14/05, s.l; Tetuán 26 de mayo de 1932; Tánger, 16 de octubre de 1932. Agradezco a Dña. Carmen Hernández Pinzón, representante de los herederos de Juan Ramón Jiménez, los permisos necesarios para acceder a este fondo así como la información y material que me ha proporcionado para la elaboración de este trabajo.
} 

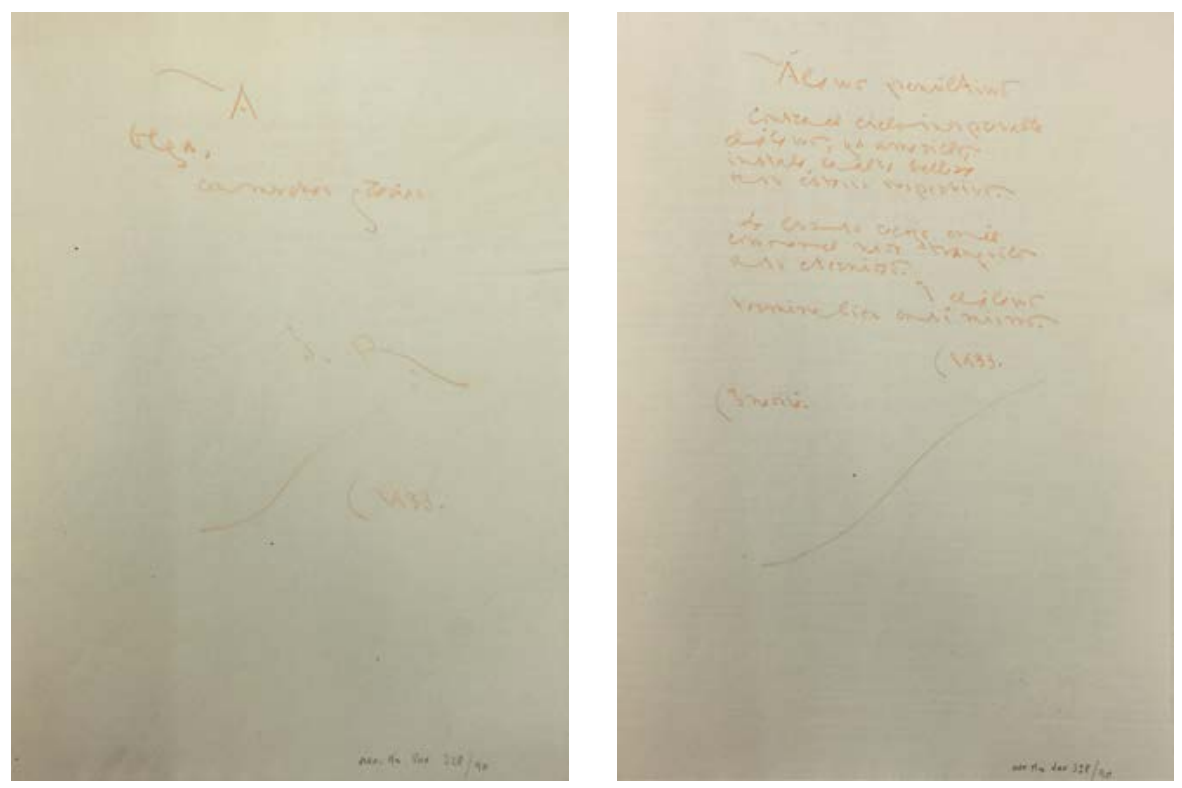

Fото 3. «A Olga, con muchas gracias, J.R., 1933»

(C) Biblioteca Nacional de Israel. ARC, Ms. Var 3280290

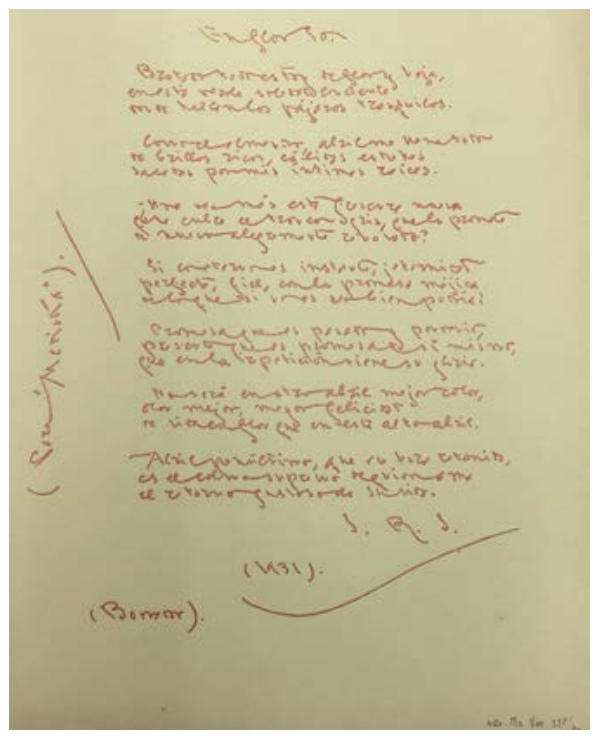

Fото 4. «En flor 50»

(C) Biblioteca Nacional de Israel. ARC, Ms. Var 3280290 
los versos "La copla [sic] final" que, en el tan lejano 1933, me dio Juan Ramón, como obra inédita, escrita por él mismo, y que yo guardo como mi mayor tesoro. Me parecía vivir nuevamente en este tiempo pasado, encontrarme en tu saloncito tan acogedor, seguir con vosotros la puesta de sol camino de la Sierra. Para mí es absolutamente indispensable estar nuevamente con vosotros, y esta separación se me hace terriblemente larga (Cortés 2017, 171).

\section{El caso de Marga Gil de RoËsSet}

Un episodio especialmente dramático que marcó la vida de Juan Ramón y Zenobia está relacionado también con su amistad con Olga Bauer. Se trata del suicidio de la escultora, pintora y escritora Margarita Gil de Roësset, cuyo diario íntimo recoge su profunda admiración por Juan Ramón (Jiménez 2015). Marga y Consuelo Gil de Roësset, su hermana, entraron en el círculo de amistades de los Jiménez de mano de Olga Bauer, en la ya aludida cena organizada por esta en homenaje a la pianista Ania Dorfmann. Se desconoce cuál fue la relación de Olga con las hermanas Roësset, pero lo cierto es que durante los años 1931-1932, Marga y Consuelo, «las niñas», como Juan Ramón Jiménez las llamaba, lo acompañaron frecuentemente, incluso durante la ausencia de Zenobia con motivo de su viaje por Marruecos. Como es sabido, esta cercana y artística relación provocó el enamoramiento de Marga por Juan Ramón Jiménez y su decisión fatal de quitarse la vida en el mes de julio de 1932. El impacto que supuso la muerte de Marga fue tremendo para los Jiménez, que no dejaron de recordarla desde entonces, pero también debió de serlo para la propia Olga Bauer, ya que, a fin de cuentas, los había presentado por primera vez. Esta idea puede corroborarse con un testimonio de la propia Olga ${ }^{7}$. Se trata de un breve cuento manuscrito en el que Olga Bauer recrea un episodio muy similar a lo ocurrido con Marga. Aunque no tiene fecha y no hay alusiones directas a este hecho, no cabe duda de que pudo tratarse de un modo de ficcionalizar -y con ello de superar y asumir personalmente- este terrible acontecimiento que tanto impacto tuvo en el círculo de amistades de los Jiménez. En el relato, Olga describe en tercera persona a una compañera de clase, Moussía, con quien apenas tiene trato, pero que le inspira un extraño interés. El motivo central de la narración es la muerte de Moussía. Su inesperada ausencia a las clases se transforma en la noticia de su envenenamiento; Olga describe cómo fueron a despedirse de ella, la impresión que su cuerpo inerte había producido en ella y la lástima por no haberla podido conocer más:

En clase estaba sentada delante de mí. Tenía una nariz larga y fina, ojos tristes, que se encendían de repente de malicia, trenzas siempre desordenadas. Al recitar su lección, que no sabía nunca, ataba y desataba sus largos y delgados dedos o

\footnotetext{
${ }^{7}$ Archivo Histórico Nacional. Fondo Juan Ramón Jiménez. Caja 40. 396/1-396/6, s.d.
} 
con un gesto nervioso alisaba el pelo detrás de sus orejas. Las clases la aburrían, no tenía reloj y a cada instante me preguntaba por la hora en voz baja.

Sus continuas interrupciones me irritaban y le contestaba de mal humor. 'No te enfades', me dijo un día con voz tan afectuosa que me puse colorada de vergüenza por mis respuestas cortantes. Teníamos poca intimidad. Un día nos encontramos en un concierto ${ }^{8}$. Parecía otra. Su traje blanco hacía resaltar su cutis tan igual, sus ojos oscuros estaban pensando, toda ella era un apasionado oír, de su ademán era ausente el descuido que me molestaba tanto en clase. Nos saludamos como amigas íntimas. Me prometí no perder nunca la paciencia con ella y esperaba la ocasión de demostrárselo.

Pero Moussía ${ }^{9}$ no vino a clase el día siguiente. Un poco más tarde supimos que se había muerto. No nos dijeron la causa, pero entendimos por frases sueltas, dichas por la institutriz, que se había envenenado.

Nos llevaron a despedirnos de ella. Era el primer cuerpo inanimado que veía. Estaba cubierta de flores blancas, que cercaban su cara tan delicada. Su nariz parecía más larga y la expresión era la del concierto. No había pensado yo nunca en cómo sería un cuerpo muerto, me impresionó profundamente la ausencia de calor y la completa majestuosa calma. '¡Cómo se ha estropeado ya!', dijo la institutriz. No comprendí el sentido de las palabras, pero la frase me hizo un daño horrible.

Al día siguiente, en el colegio, las niñas hablaban del entierro. Yo no me podía perdonar de no haber conocido más a Moussía. Su amiga, que no me había sido nunca simpática, estaba sola, desconsolada, las otras chicas no parecían notarlo. Me fui al rincón donde se había escondido y lloré con ella amargamente la amiga desaparecida.

Este relato, hasta ahora inédito, refleja la afición de Olga por la escritura de textos ficcionales de inspiración autobiográfica. Además de este testimonio, se conservan otros siete relatos de Olga Bauer relacionados, en su mayor parte, con algunas experiencias de juventud, y escritos bajo la influencia de la poesía juanramoniana durante sus años de amistad con los Jiménez: La formación de Olga, La revolución de octubre, Otoño en Petrogrado, Nieve, Noches blancas, Llanura infinita y amarillenta, La recolección de setas y Rincón de Ámsterdam (Cortés 2017, 793-800).

\section{AMistad más ALLÁ DEL EXILIO}

A partir de 1936 y durante todo el exilio de Juan Ramón y Zenobia en América la correspondencia entre Olga y Zenobia fue constante. El epistolario

\footnotetext{
${ }^{8}$ Nótese que se trata del mismo contexto en el que, a través de Olga Bauer, Margarita Gil de Roësset conoció a Zenobia y a Juan Ramón.

${ }^{9}$ La elección del nombre Moussía no parece casual. Se trata de una forma hipocorística del ruso «Mushka». Olga podría haberse inspirado en el de Hayyah Mushka (Moussía) Schneerson (1901-1988) la mujer de uno de los grandes líderes del hasidismo ruso, Rebbe Menachem Mendel Schneerson, que tanta influencia tuvo en el movimiento Habad-Lubavitch.
} 
conservado entre ambas arroja innumerables y exquisitos detalles sobre esta amistad y sus circunstancias vitales a través del tiempo. En esta ocasión, me gustaría simplemente destacar algunas noticias que pueden marcar las líneas y contenidos generales de esta correspondencia ${ }^{10}$.

En otros epistolarios publicados con anterioridad, las alusiones a las cartas que Zenobia recibía de Olga son muy frecuentes. Esta le informaba puntualmente de sus proyectos y de otras novedades, bien desde Suiza o desde Holanda. Las preocupaciones por los acontecimientos bélicos en España, así como la inestable situación de Ignacio y Olga fueron dos de los temas que más aparecen en sus cartas. El 27 de agosto 1937, Zenobia recibía de ella la noticia de que Santiago Alba, ministro durante la Monarquía y presidente del Congreso durante la Segunda República, estaba tratando de concordar la paz entre las facciones enemigas (Palau de Nemes 2006a, 86). Pocos meses antes, recibía otra carta de Olga informándole de la posibilidad de establecerse en Cuba, aunque, en palabras de Zenobia, «no sé qué harían para trabajar aquí, y claro, un ruso en simpatía con el gobierno sería inmediatamente declarado comunista y probablemente encontraría cerradas todas las puertas» (Palau de Nemes 2006a, 51). El 22 de marzo de 1938, y dadas las circunstancias que se vivían en Europa, Olga Bauer rogaba a los Jiménez no regresar. Ella, aconsejada por Zenobia, se había establecido por entonces en Holanda con su padre. En otras ocasiones, Olga le informaba puntualmente del estado de sus conocidos: «Olga me cuenta de las muertes de Chunga y la hija mayor de los Llovera y de Carmen Espinosa de los Monteros» (Palau de Nemes 2006b, 220). En 1940, con carta fechada en Lavardac el 20 de junio y el matasellos de Burdeos del 1 de julio Olga comunicaba a Zenobia su próxima llegada a Madrid (Palau de Nemes 2006b, 213). La correspondencia fue continua durante estos años y en ella se refleja la preocupación de los Bauer por el anhelado regreso de los Jiménez a España. Desde Âmsterdam, el 1 de septiembre de 1939, escribía a Juan Ramón Jiménez, informándole de algunas gestiones que Ignacio había realizado con el fin de facilitar su posible traslado a París, tratando de convencerle de que algún día, y a pesar de la guerra, volvería (Crespo y González, 2009, 408-410):

Querido Juan Ramón, su carta llegó rápidamente y nos hemos ocupado del asunto enseguida. No he podido hacer nada personalmente por la Legación de París, pero Ignacio ha encontrado un medio mejor, por intervención de personas de aquí y ha escrito enseguida a la Señora de N[avarro] Tomás, explicando lo que tenía que hacer. Sin embargo, temo que no sea favorable la cosa, pues he sabido ayer

${ }^{10}$ No he tenido acceso a las cartas originales de Olga Bauer y Zenobia Camprubí, de cuya existencia me ha informado Carmen Hernández Pinzón. Estas han sido publicadas por Cortés Ibáñez (2017) tiempo después de la redacción y aceptación de este artículo, por lo que no se han podido tener en cuenta en su integridad, salvo contadas excepciones. Espero que esta contribución pueda complementar mínimamente la magnífica edición realizada por la Dra. Cortés Ibáñez. 
por la noche que se exige una garantía del barco referente a la certeza de su salida desde Holanda y, claro está, en las circunstancias actuales esta garantía es casi imposible [...].

No diga que no vuelve más. Todo cambia, en España más que en otros países o quizá sería más justo decir, que nunca cambia allí y que siempre se vuelve a las mismas cosas absurdas y criminales. Y sin embargo, yo tengo la sensación que es el único país donde se puede vivir, el único país en donde la gente tiene dignidad individual, que alguna vez no es aparente, pero existe en el fondo. Lo único es que hay que buscar justamente esta gente, que es superior a la de otras naciones. Creo que Vd. tiene el secreto de descubrir lo que es verdadero y eterno en cada uno y por eso tiene $\mathrm{Vd}$. amigos leales y reales más que otros.

No me diga que no vuelve a España, pues me desola pensar en ello. Yo, por mi parte, creo que el único sitio para mí es justamente España, a pesar de todos los farsantes, que siempre han existido allí y existirán siempre.

Lo que está pasando ahora en el mundo entero es horrible y temo que cuando le llegue esta carta ya habrá empezado la guerra y el final de toda nuestra vida. Lo único que queda es, como dice Vd. la familia y la amistad. Con afectuosos abrazos a los dos, suya Olga.

La muerte de Zenobia en 1956 motiva la última carta de Olga Bauer a Juan Ramón Jiménez. Ya desde su residencia habitual en Basilea, en la calle Rennweg 75, donde vivía junto con Ignacio, su hermana Vera y su sobrina Katia Guth, escribía en francés a Juan Ramón lamentando el fallecimiento de su mujer (Alegre 2008, 387):

Mi querido Juan Ramón:

ahora mismo me llega la noticia. Usted sabe el afecto que he tenido siempre para Zenobia y para usted, sabe también lo que significaba para mí Zenobia. Sé su dolor y le pongo estas letras para decirle que estoy con usted en su desesperación. Le debe servir de consuelo que la noticia del Premio Nobel fue una última satisfacción para Zenobia, para ella que desde siempre sabía que tenía que ser para usted.

Con Ignacio le enviamos nuestra simpatía más honda y todo nuestro afecto. Olga.

\section{Círculos literarios}

Los logros de Olga Bauer en el campo de la cultura literaria española fueron más allá de los vínculos personales con Zenobia Camprubí. Desde un segundo plano, ella participó activamente en la vida cultural del país durante decádas, impulsó la creación de nuevos proyectos literarios y conservó sus amistades madrileñas. Recordaba Enrique Canito, fundador de la revista Ínsula , cómo Olga Bauer, a quien había conocido en la Universidad Internacional de Santander, había asegurado la vertiente internacional de la revista «con su dominio de varias lenguas, con su sensibilidad exquisita, con su asiduo y paciente servicio. Doña Olga fue el alma y el comienzo de aquellas reuniones 
frecuentes de amigos que habían de culminar en la tertulia de los miércoles de Carmen, 9» (Núñez 1970, 27; Cortés 2017, 31-34). Una tarea que siguió realizando fuera de España, dedicándose fundamentalmente a la edición de literatura contemporánea inglesa y francesa ${ }^{11}$. En 1954, escribió además un libro sobre cortesía y etiqueta modernas que contó con una notable aceptación en la época y varias reediciones (Garzón 2011, 36) ${ }^{12}$.

Desde Basilea y en sus esporádicas estancias en Madrid, Olga siguió manteniendo una estrecha relación con muchos escritores e intelectuales. En 1956, durante la visita de Julián Marías a Juan Ramón y Zenobia en Puerto Rico, todos evocaban cómo se habían conocido en la casa madrileña de Olga Bauer (Palau de Nemes 2006b, 312). La situación se la recordaba Zenobia a Olga en carta de 21 de junio de 1956 con motivo de la publicación hebrea de Platero y yo:

Anteayer vino a vernos Julián de (sic) Marías, que: «Usted no se acordará de mí pero yo la conocí en casa de $\mathrm{O}(\operatorname{lga}) \mathrm{B}($ auer)». Y yo le contesté indicando tu retrato: «Y aquí la tenemos con nosotros también» y le enseñé el Platero israelí que me acababas de mandar (Cortés 2017, 781) ${ }^{13}$.

El mismo Juan Ramón Jiménez relataba a Ricardo Gullón cómo había pedido a Olga unos libros sobre el reciente descubrimiento de los manuscritos del Mar Muerto (Gullón 2008, 98). Del mismo modo, mantuvo correspondencia con Jorge Guillén, a quien desde su residencia en la calle Alfonso XII, 58, escribía el 10 de mayo de 1958 con motivo del fallecimiento de su padre:

Muy estimado amigo, me entero de su desgracia y con esas líneas me apresuro asociarme a su inmenso dolor. Sé cuál estrechos han sido los vínculos que le unían a su padre y sé por experiencia lo triste que es encontrarse de repente sin nuestros tan queridos mayores. Sentí tanto no haber podido verle en ¿Blois? ${ }^{14}$ este verano, pero me enteré de su estancia demasiado tarde, unas horas antes de marcharme, pero tuve el gran gusto de conocer a su hijo en Madrid. Deseando poder verle en otra ocasión, le envía sus muy afectuosos recuerdos. Olga Bauer ${ }^{15}$.

11 Debe recordarse que antes de la Guerra, Olga era una traductora reconocida, con examen aprobado por la Secretaría Auxiliar de la Dirección General de Primera Enseñanza (Centro Documental de la Memoria Histórica, PS-Madrid, 2463, 194).

12 Olga Bauer, Cortesía y etiqueta modernas, Madrid: Aguilar, 1954. Reediciones en 1956, 1959, 1962 у 1967.

${ }^{13}$ El 12 de julio de 1956 Olga Bauer escribía a Zenobia una semblanza del mismo: Julián Marías es gran amigo mío desde hace años. Le conocí cuando era muy joven y, desde entonces, he seguido su carrera con gran interés. Es un hombre que vale, muy culto y honrado $\mathrm{y}$, durante estos últimos años, fue una de las pocas personas con quien se podía hablar y discutir. Sigue desarrollándose y tiene la facultad de entender el pensamiento ajeno sin por ello perder su propia personalidad. En los últimos años fue el gran apoyo de Ortega y Gasset, y su fiel admirador y amigo (Cortés 2017, 784).

${ }^{14} \mathrm{La}$ lectura es dudosa.

15 Biblioteca Nacional de España, Fondo Jorge Guillén 9/7. 
La colaboración de Olga con Juan Ramón y Zenobia en sus proyectos literarios es especialmente significativa en lo que respecta a la edición en hebreo de Platero y yo, publicada en 1956 por Enmanuel Olsvanger (1888-1961), uno de los traductores israelíes más reconocidos en ese momento ${ }^{16}$. Olsvanger se había puesto en contacto con los Jiménez en 1951 para proponer una traducción de esta obra solicitando la exención de los derechos de autor. La propuesta se prolongó en el tiempo sin resultados palpables y, desde el principio, provocó los recelos de Zenobia ante la petición de este de publicar la traducción sin beneficio alguno para el matrimonio. Esta cuestión fue un motivo recurrente en varias cartas entre Zenobia y Olga durante la década de los años cincuenta; a través de las mismas puede reconstruirse el tedioso proceso que supuso la edición hebrea del libro. En su correspondencia con Olga Bauer, Zenobia no disimuló el enojo que le había producido la inconsistencia y falta de profesionalidad de Olsvanger. Así, en carta de 18 de febrero de 1954, Zenobia le preguntaba por el estado de la traducción de Platero y yo que Olsvanger había prometido, pero de la que no tenía ninguna noticia desde hacía tres años:

Aunque no voy a enviarte ésta enseguida, quiero iniciarla para que no se me olvide decirte que, si tienes ocasión cuando estés en Israel de ver al Sr. Olsvanger, no dejes de preguntarle cómo anda su traducción de Platero y yo. Este señor le pidió permiso a J.R. en mayo del 51 para traducir al hebreo este libro. Como dijo que hacía tres años se había publicado La Divina Comedia -Il Inferno- y tenía a punto de publicación Il Purgatorio, pensamos que era hombre de constancia y voluntad. Nos escribió en papel de The British Interplanetary Society, Astronomical Section y sus señas eran: 3 Goya Road, Jerusalem. No vayas a darte gran pena por esto pero a lo mejor, puedas telefonearle. El señor quería que le regaláramos los derechos pues que iba a publicar «con hambre y sin dinero», pero yo le contesté que, en vista de eso, nos conformaríamos con pedirle solo $\$ 50$ por una $1^{\mathrm{a}}$ edición de 1.000 ejemplares y que, si esta se vendía, volveríamos a hablar. Lo cierto es que, desde entonces, se han publicado traducciones al holandés y al alemán y al ruso y la tercera traducción al italiano, la noruega y la inglesa están en camino pero el Sr. Olsvanger no ha vuelto a chistar. También, si estás en una librería, me gustaría que preguntaras si este libro ha salido (Cortés 2017, 646-647).

Pocos meses después de la petición de su amiga, Olga Bauer lograba contactar en Jerusalén con Olsvanger. El 21 de marzo de 1954 le informaba de

${ }^{16}$ Olsvanger, de origen polaco, escritor y traductor, dominaba más de dieciocho lenguas. Se estableció en Israel en 1933 y fundó la editorial Tarsis. Ferviente sionista, entre 1936 a 1939 vivió en el sur de Asia como delegado del Kéren ha-Yesod y allí aprendió sánscrito y japonés. Su conocimiento de la obra de Tagore pudo incitarle a contactar con los Jiménez. La primera edición hebrea, con múltiples ilustraciones realizadas por Iris Schweitzer, data de 1956 y fue reeditada en 1963, פלטרו ואני, (Tel Aviv: Am Oved). Cinco fragmentos del libro fueron traducidos por Shmuel Regulant y Ofra Banjo en el no 267 del periódico 'Iton 77, Tel-Aviv, mayo, 2002. La última traducción hebrea ha sido realizada por Rami Sa'ari en 2006 (Jerusalem: Carmel). 
que, como él mismo le había referido, la edición estaba ya acabada y a punto de imprimirse, por lo que su aparición parecía inminente:

Acaba de salir el Sr. Olsvanger, que tuve cierta dificultad en localizar y que es un viejo lleno de entusiasmos literarios. Platero debe ir a la imprenta dentro de pocos días y aparecerá próximamente. Parece ser que la dificultad que se ha presentado es el poder enviar el dinero pues, a pesar de la exigüidad de la suma, no se ha conseguido aún el permiso oficial para efectuar el envío. Sin embargo espera, que se terminará obteniéndolo. Dice que te escribió a Washington y le he dado tus señas actuales (Cortés 2017, 649).

En mayo de 1954 Olsvanger había expresado a Olga su deseo de que el Platero hebreo apareciera en septiembre, coincidiendo con las festividades mayores del calendario judío (Cortés 2017, 656); y en 1955, volvía a prometerle el envío de su traducción (ibíd., 701). A pesar de ello, la edición se demoró aún un año más: salió a la luz en el mes de abril de 1956, tal y como Olga Bauer se apresuró a comunicar a Zenobia en carta de 8 de abril desde Haifa:

Al llegar aquí, me llega el ejemplar de Platero en ivrit, que acaba de aparecer hace dos días. Di orden para que te lo enviaran enseguida. Ya me dirás cómo te parece la edición. Me he puesto a leerlo pero me será más fácil hacerlo luego en Basilea, teniendo a mano el texto castellano (Cortés 2017, 771).

El 17 de abril de ese mismo año enviaba a Zenobia una nota sobre su publicación, expresando su deseo de que se reseñara en The Jerusalem Post e informándole también del interés de una conocida suya en Israel por redactar un artículo sobre el libro en una revista local (Cortés 2017, 773-774). A pesar de las dificultades, este anuncio de la versión hebrea de Platero y yo alegró mucho a Juan Ramón (Palau de Nemes y Cortés 2006, 1186). Pero la prensa israelí apenas se hizo eco de la obra, salvo en algunas secciones de información bibliográfica sobre obras literarias recién publicadas para niños ${ }^{17}$.

Zenobia no recibió con entusiasmo la edición: «El fresco del editor se ha lanzado sin contrato» (Cortés 2017, 775), y comunicaba el 24 de mayo de 1956 a Olga su deseo de perseguir el modo en el que Olsvanger había publicado el libro sin haber tenido en cuenta los derechos de autor que ella había exigido desde el principio:

Ahora te voy a pedir un favor. Te copio dos párrafos de mi carta del $1^{\circ}$ de mayo del 51, que haré fotocopiar o copiar a máquina mañana o pasado, y te mandaré enseguida. La carta es para Olsvanger:

(en inglés): «En cuanto a la publicación de 'los rebuznos de Platero' en hebreo, ha delegado en mí. Como sugieres que es 'con hambre y sin dinero', me gustaría

17 'Al Ha-Mishmar, 27 de abril 1956; Ha-Haretz, 10 de diciembre 1956. 


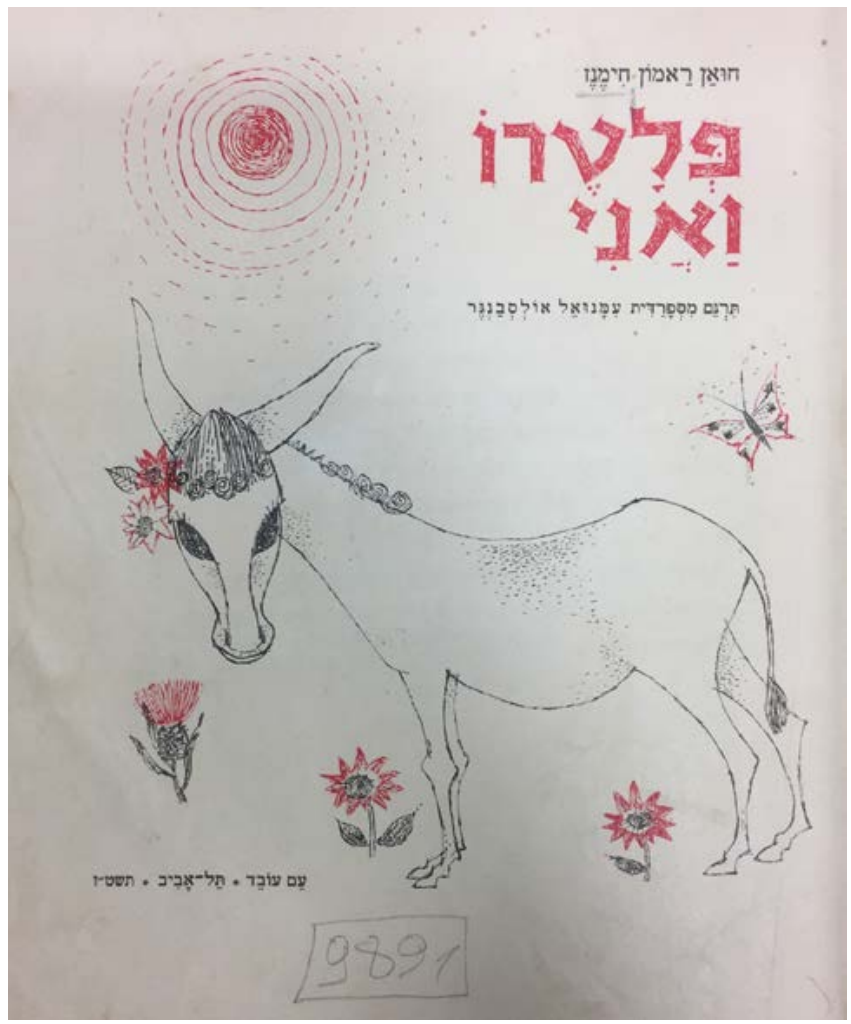

Foto 5. Platero wa-'Ani, Tel Aviv, 1956

(C) Biblioteca Nacional de Israel, Sign. 56 A 1229

decir que un poeta está acostumbrado a ambas cosas, si sus libros no tienen éxito. Nosotros siempre hemos tenido que pagar para traducir la obra de otros poetas, con la única excepción de J. M. Synge -el exquisito autor irlandés-pero anualmente recibimos docenas de cartas con la proposición de que mi marido autorice traducciones sin remuneración. Por esta razón sugiero que autorice una primera edición limitada de no más de 1.000 ejemplares con un pequeño adelanto de $\$ 50$ $\mathrm{y}$, cuando veamos cómo funciona, hablaremos».

Después de cinco años este sinvergüenza da una edición bastante lujosa de trescientos ejemplares y no nos manda uno para que no nos enteremos de que nos está robando descaradamente. Dime cuál es la mejor manera de meterle en cintura. Espero tu carta para empezar en el acto a perseguirle. Es mejor ir por la Embajada española y, si así, ¿quién es el actual embajador y las señas?, ¿querrías empezar por hablarle por nosotros y escribirnos lo que él dice (ibíd., 777-778).

Un mes después, y con motivo del envío de algunos ejemplares que Olga les había enviado a Puerto Rico, insistía de nuevo sobre la cuestión: 
No te he mandado el importe de los libros que te pedí porque tú no sabes lo que me cuesta, desde la cama, toda gestión. Gracias por lo que me dices del cónsul y voy a ver si pongo al vicecónsul de aquí a trabajar en un asunto. Ya sé que no vale la pena por el dinero pero me da coraje la sinvergonzonería de los que usan el cerebro ajeno para comerciar con él robándose el producto material (ibíd., 780).

Se desconoce cómo se resolvieron finalmente las protestas que Zenobia pretendía dirigir al cónsul de Palestina, tal y como Olga le había recomendado, y a pesar de la extrañeza que esta mostraba ante el comportamiento de Olsvanger: «Me parece muy bien el haber encargado el asunto de la traducción israelí del Platero al consulado, pues es el camino más directo, y espero que te complacerán. Olsvanger no tiene mala fama y no comprendo su actitud tan fea» (ibíd., 784).

\section{Conclusiones}

Las noticias aportadas permiten considerar a Olga Bauer como una de las mejores amigas de Zenobia Camprubí y una figura de excepcional interés en el desarrollo de la vida cultural española de la primera mitad del s. XX. Su ininterrumpida relación de amistad, que se prolongó durante más de dos décadas, sus intereses comunes por la cultura y literatura hispánicas así como su capacidad de abrir nuevos espacios de participación de la mujer en los ambientes intelectuales de la época, no han sido lo suficientemente valorados hasta ahora. Quedarían muchos otros detalles por precisar de la biografía de Olga Bauer, en especial, aquellos relacionados con su implicación en el desarrollo de la vida comunitaria judía de los años veinte y de la Guerra Mundial, sus frecuentes visitas a Israel y su círculo de amistades jerosolimitanas y que abordaré en un próximo trabajo. Pero lo ofrecido en esta ocasión es lo suficientemente significativo como para poner de manifiesto la necesidad de seguir ahondando en las aportaciones personales de algunas mujeres judías de la España contemporánea que, por las propias circunstancias que les tocó vivir, han quedado relegadas al caprichoso silencio de la historia.

\section{BiBLIOGRAFÍA CITADA}

Alegre Heitzmann, Alfonso. 2008. Juan Ramón Jiménez, 1956. Crónica de un Premio Nobel (Memoria, cartas y documentos). Madrid: Publicaciones de la Residencia de Estudiantes.

Azzam, Gilbert. 1981. «La Estación total de J.R. Jiménez o la plenitud radiante». Boletín de la Real Academia Española LXI, 224: 457-480.

Capdevila-Argüelles, Nuria. 2013. Artistas y precursoras. Un siglo de autoras Roësset. Madrid: Horas y Horas.

Chernow, Ron. 1993. The Warburgs: The Twentieh-century Odyssey of a Rearkable Jewish Family. New York: Random House. 
Cortés Ibáñez, Emilia, ed. 2012. Diario de dos reciencasados. Zenobia Camprubí y Juan Ramón Jiménez. Huelva: Servicio de Publicaciones Universidad de Huelva - Fundación Zenobia Juan Ramón Jiménez.

Cortés Ibáñez, Emilia, ed. 2015. Zenobia Camprubi. Diario de Juventud. Escritos. Traducciones. Madrid: Fundación José Manuel Lara.

Cortes Ibáñez, Emilia, ed. 2017. Zenobia Camprubí - Olga Bauer. Epistolario 1932-1956. Huelva: Servicio de Publicaciones Universidad de Huelva - Diputación de Huelva.

Crespo, Ángel y Santiago González Ródenas, eds. 2009. Juan Ramón Jiménez. Guerra en España. Prosa y verso (1936-1954). Sevilla: Point de Lunettes.

Cuesta, Josefina, María José Turrión y Rosa María Merino, eds. 2015. La Residencia de señoritas y otras redes culturales femeninas. Salamanca: Ediciones Universidad de Salamanca - Fundación José Ortega y Gasset - Gregorio Marañón.

Cueva, Almudena de la y Margarita Márquez Padorno, eds. 2015. Mujeres en vanguardia: La Residencia de Señoritas en su centenario [1915-1936]. Madrid: Publicaciones de la Residencia de Estudiantes.

Díaz de Castro, Francisco José. 2007. «La estación total». Cuadernos hispanoamericanos 685-686: 127-134.

Domínguez Sío, María Jesús. 2008. «Cartas Marruecas. De Zenobia a Juan Ramón: Tetuán». Revista Ateneu. Revista cultural de Malgrat i l'Alt Maresme 31: I-IX.

Domínguez Sío, María Jesús. 2010. «Cartas Marruecas II (de Zenobia a Juan Ramón)». En Mujer y escritura autobiográfica: Zenobia Camprubí, ed. Emilia Cortés Ibáñez. Huelva: Diputación Provincial de Huelva.

Frankel, Jonathan. 1981. Prophecy and Politics: Socialism, Nationalism, and the Russian Jews, 1862-1917. Cambridge: Cambridge University Press.

Garzón, Jacobo Israel. 1996. «Ignacio Bauer y Landauer: primer presidente de la Comunidad Israelita de Madrid». Raíces 29: 31-35.

Garzón, Jacobo Israel. 2001. «Panorámica de la comunidad judía de Madrid en el siglo XX». En La comunidad judia de Madrid. Textos e imágenes para una historia 1917-2001, ed. Jacobo Israel Garzón y Uriel Macías Kapón, 25-54. Madrid: Comunidad Judía de Madrid.

Garzón, Jacobo Israel. 2011. Bauer y Mansberger. Dos familias españolas de origen judío entre los siglos XIX y XXI. Madrid: Hebraica Ediciones.

Gesser, Silvina Schammah. 2015. Madrid's Forgoten Avan-Garde: Between Essentialism and Modernity. Eastbourne, UK - Chicago IL: Sussex Academic Press.

Gullón, Ricardo. 2008. Conversaciones con Juan Ramón Jiménez. Sevilla: Sibilina - Fundación BBVA.

Jiménez, Juan Ramón, ed. 2015. Marga. Madrid: Fundación José Manuel Lara.

Lisbona, José Antonio. 1993. Retorno a Sefarad. La política de España hacia sus judios en el siglo $X X$. Barcelona: Ríopiedras.

López-Morell, Miguel Ángel y Antonio Molina Abril. 2012. «La Compañía Iberoamericana de Publicaciones, primera gran corporación editorial en castellano». Revista de Historia Industrial XXI (49): 111-145.

Maier, Jorge. 2005. Catálogo del Gabinete de Antigüedades. Siglos XVI-XX. Madrid: Real Academia de la Historia.

Núñez, Antonio. 1970. «La pequeña historia (Ínsula, 1946-1970)». Ínsula. Revista Bibliográfica de Ciencias y Letras XXV, 284: 25-30.

Ortiz de Urbina y Sobrino, Paloma. 2005. La recepción de Richard Wagner en Madrid (1911-1914). Madrid: Universidad Complutense de Madrid.

Palau de Nemes, Graciela, ed. 2006a. Zenobia Camprubi. Diario 1. Cuba (1937-1939). Madrid: Alianza Editorial. 
Palau de Nemes, Graciela, ed. 2006b. Zenobia Camprubí. Diario 2. Estados Unidos (19391950). Madrid: Alianza Editorial.

Palau de Nemes, Graciela y Emilia Cortés Ibáñez. 2006. Zenobia Camprubí. Epistolario I. Cartas a Juan Guerrero Ruiz, 1917-1956. Madrid: Publicaciones de la Residencia de Estudiantes.

Pérez Villanueva Tovar, Isabel. 2011. La Residencia de Estudiantes, 1910-1936: grupo universitario y residencia de señoritas. Madrid: CSIC - Publicaciones de la Residencia de Estudiantes.

Ribagorda, Ángel. 2009. Caminos de la modernidad. Espacios e Instituciones Culturales de la Edad de Plata (1898-1936). Madrid: Editorial Biblioteca Nueva - Fundación Ortega y Gasset.

Sánchez García, Raquel. 2003. «Juan Ramón Jiménez y el mercado editorial». Dicenda. Cuadernos de Filología Hispánica 21: 301-318.

Sánchez-Gómez, Luis Ángel. 1990. «La sociedad española de Antropología, Etnografía y Prehistoria (1921-1951)» Revista de Dialectología y Tradiciones Populares XLV: 63-87.

Fecha de recepción: 15 de julio de 2017.

Fecha de aceptación: 25 de enero de 2018. 